\title{
Personality profiles of patients with alcohol and drug misuse in a Nigerian treatment facility
}

\author{
T. A. Adamson MRCPsych FWACP FMCPsych, ${ }^{1}$ P. O. Onifade MBBS FMCPsych, ${ }^{2}$ \\ O. I. Ibikunle $\mathrm{MSc}^{3}$ and E. B. Somoye $\mathrm{MBBS}^{4}$
}

${ }^{1}$ Chief Consultant Psychiatrist, Drug Addiction Treatment Education and Research unit (DATER), Neuropsychiatric Hospital, Abeokuta; ${ }^{2}$ Consultant Psychiatrist, DATER, Neuropsychiatric Hospital, Abeokuta, Nigeria, email oniffpo@yahoo.com ${ }^{3}$ Clinical Psychologist, DATER; ${ }^{4}$ Senior Registrar, DATER

D rug dependence treatment in Nigeria is at an early stage of development. The first 'stand alone' drug dependence treatment in-patient unit in Nigeria, the Drug Addiction Treatment Education and Research (DATER) unit, Aro, Abeokuta, Nigeria, was established in 1983. Prior to this, patients with drug dependence received care along with other patients in psychiatric wards and traditional healing homes (United Nations International Drug Control Programme, 1998). Currently, there is no national body in Nigeria actively involved in regulating or facilitating good practice in drug dependence treatment.

Personality may be viewed as the characteristic pattern of feelings, thinking, perception and behaviours that defines the interaction of an individual with the environment. Several studies have shown associations between substance use and personality, the latter influencing both the aetiology and the course of the former (Verheul, 2001). The DATER unit, in an effort to improve treatment outcomes, commenced the routine personality assessment of all its patients in 2004, as part of the admission procedure. The present study set out to identify common personality attributes of the patients treated over a 5-year period in the DATER unit.

\section{Method}

This cross-sectional study involved all consecutive patients admitted to the DATER unit of the Neuropsychiatric Hospital, Abeokuta, between 2004 and 2008. The unit is a 26-bed 'stand alone' drug dependence treatment ward. A detailed description of the unit has been given by Makanjuola (1986). The treatment programme is eclectic, incorporating detoxification, relapse prevention and treatment approaches based on the therapeutic community model and the Alcoholics Anonymous programme. Patients were admitted for 6-9 months.

All patients admitted to the unit had a clinical psychiatric interview and diagnoses were made according to ICD-10 criteria (World Health Organization, 1992). Those with current comorbid mental disorders were treated in the general psychiatric wards of the hospital before admission to the DATER unit. Integral to the admission procedure, all patients signed a contract agreement and gave informed consent for treatment and various laboratory and psychological investigations, including the Minnesota Multiphasic Personality Inventory (version 2, MMPI-2; Graham, 1993).
The patients received the MMPI-2 within the first 2 weeks of admission. None withdrew consent during the study period.

The MMPI-2 is the most widely used and researched personality assessment instrument; it was originally intended to assign psychiatric diagnoses to patients. However, it describes personality profiles rather than personality disorders (Graham, 1993). Eight of its ten clinical scales were based on patients with specific psychiatric diagnoses; however, studies showed that the clinical scales were not the pure measures of symptom syndromes suggested by the scale names. To prevent the erroneous interpretation of the scales on account of their titles, numbers were assigned to the scales instead (Graham, 1993).

Each scale has several items, which generate a raw score, which for purposes of percentile comparability and interpretation is mathematically converted to a uniform $T$ score. The uniform $T$ score has a mean of 50 and a standard deviation of 10; however, because of the positively skewed nature of the $T$ score distribution, scores of 65 and 70 have percentile equivalences of 92 and 96 respectively (Butcher et al, 2001). A high $T$ score ( $>65$ ) on a clinical scale suggests psychopathology but not necessarily a psychiatric diagnosis. It also suggests a personality profile, both for individuals with and for those without a psychiatric diagnosis (Butcher et al, 2001). Since interpretation based on more than one clinical scale gives a better personality description (Graham, 1993), a two-point MMPI-2 code type was used for the interpretations in this study. This code type denotes the two clinical scales (i.e. excluding scales 0 and 5) with the highest scores (not necessarily over 65). Each two-point code type has researchbased descriptors highlighting the personality profiles of the individual (Graham, 1993).

\section{Results}

\section{Sociodemographic and clinical variables}

Ninety-one consecutive patients participated in the study. Their ages ranged between 18 and 57 years; their mean (SD) age was 32.0 (9.9) years. As shown in Table 1, most were male (92\%), single (76\%) and unemployed (71\%); 59 (65\%) had completed secondary school education. More than half the participants had comorbid mental disorders, the most prevalent diagnosis being schizophrenia (45\%). The most common main drug of misuse was marijuana (55\%), followed by alcohol (26\%). 
Table 1 Sociodemographic and clinical variables $(n=91)$

$\begin{array}{lrr} & n & \% \\ \text { Variable } & & \\ \text { Gender } & 84 & 92 \\ \text { Male } & 7 & 8 \\ \text { Female } & & \\ \text { Marital status } & 69 & 76 \\ \text { Single } & 13 & 14 \\ \text { Married } & 9 & 10 \\ \text { Divorced/separated } & & \\ \text { Education level completed } & 4 & 4 \\ \text { Primary } & 59 & 65 \\ \text { Secondary school } & 28 & 31 \\ \text { Tertiary } & & \\ \text { Psychiatric disorder } & 35 & 38 \\ \text { None } & 41 & 45 \\ \text { Schizophrenia } & 10 & 11 \\ \text { Bipolar affective disorder } & 5 & 5 \\ \text { Psychoses not otherwise specified } & & \\ \text { Main drug of misuse } & 50 & 55 \\ \text { Marijuana } & 24 & 26 \\ \text { Alcohol } & 15 & 16 \\ \text { Cocaine } & 2 & 2 \\ \text { Opiates } & & \\ & & \\ & & \end{array}$

Table 2 The common personality descriptors $(n=91)$

\begin{tabular}{lrr} 
Personality descriptors & $n$ & $\%$ \\
\hline $\begin{array}{l}\text { Perception of insecurity/poor self-esteem/ } \\
\text { poor self-concept }\end{array}$ & 51 & 56 \\
Distrustful of others and/or avoidance of & 48 & 53 \\
$\quad$ deep emotional ties & & \\
Impulsiveness/poor control of gratification & 32 & 35 \\
Disregard for social standards and & 32 & 35 \\
authority figures & & \\
Two-point MMPI-2 code types & & \\
(commonly associated personality problems) & & \\
4-8/8-4 (antisocial, schizoid or paranoid) & 13 & 14 \\
6-8/8-6 (paranoid, schizoid) & 10 & 11 \\
8-9/9-8 (emotional lability) & 10 & 11 \\
2-4/4-2 (antisocial) & 9 & 10 \\
2-8/8-2 (anxious, dependent traits) & 6 & 7 \\
4-6/6-4 (passive-aggressive traits) & 6 & 7 \\
4-7/7-4 (passive-aggressive traits) & 5 & 5 \\
1-4/4-1 (anxious) & 4 & 4 \\
4-9/9-4 (antisocial) & 4 & 4 \\
Others & 24 & 26 \\
& &
\end{tabular}

\section{Two-point MMPI-2 code types and personality descriptors}

The 91 patients yielded 24 different two-point MMPI-2 personality code types, nine of which occurred at least four (4\%) times. Table 2 shows the nine most common code types and the commonly associated personality problems. The code types have overlapping descriptors; for example, perception of insecurity/poor self-esteem (56\% of the patients) occurs in individuals with code types 4-8/8-4, 2-4/4-2, 6-8/8-6, 8-9/9$8,4-7 / 7-4$ and $4-9 / 9-4$. Distrust of others and/or avoidance of deep emotional ties also occurred in more than half the participants (53\%). Other common descriptors and their frequencies are shown in Table 2.

\section{Discussion}

The predominance of cannabis (55\%) over other drugs in this study is in keeping with the report by Adamson et al (2010) of a change in the pattern of drugs used by patients admitted to the DATER unit between 2002 and 2007 compared with between 1992 and 1997. They reported that the rate of cannabis use by admitted patients increased from $26.6 \%$ to $53.3 \%$, while the use of cocaine and opiates decreased from $44.0 \%$ and $22.0 \%$ to $17.1 \%$ and $8.6 \%$ respectively. They also reported significantly greater odds of presenting with comorbid mental disorders with the use of cannabis as against the use of other drugs. It appears from their report that the development of mental disorders is a key factor which makes an individual with cannabis use disorder present for treatment at the DATER unit. A majority of the patients admitted to the unit originally presented for treatment of mental disorders at the general wards of the hospital.

The two-point MMPI-2 code types in this study are similar to those reported by others. Craig (1984) reported code types 4-9/9-4, 4-2/2-4 and 4-8/8-4 as the most common among drug-dependent patients. These code types reflect high scores on the pairs of psychopathic deviate and hypomia, psychopathic deviate and depression, and psychopathic deviate and schizophrenia respectively. The code types are not synonymous with personality disorders, although certain personality disorders are commonly associated with some code types; for example, code type 4-8/8-4, the most common in this study, is often associated with antisocial, schizoid and paranoid personality disorders (Graham, 1993). To diagnose a personality disorder, however, an appropriate instrument such as the Structured Clinical Interview for DSM-IV Axis II Personality Disorders (SCID-II) would need to be administered.

The personality descriptor of poor self-esteem/concept was obtained in about half the patients. This is of clinical significance, as poor self-esteem has been associated with drug dependence, being a precursor or sequela of drug dependence and contributing to poor prognosis. In the 'self-esteem' theory of drug misuse, Steffenhagen (1980) opined that every 'behaviour is mediated by the individual's attempt to protect the "self" within the social milieu' and that "the preservation of the concept of "self" is the most important variable in understanding the initiation, continuation and cessation of drug use, and further explains why the rehabilitation process frequently results in relapse'. However, self-esteem is not the only important variable in the predisposition to and perpetuation of drug dependence, which partly explains why some of the patients with drug dependence in this study did not have poor self-esteem as a descriptor. Other variables, such as impulsivity and distrust, have also been reported (Ball, 1998), lending credence to one of the fundamental principles of drug dependence treatment, highlighted by the US National Institute on Drug Abuse (1999): 'Effective treatment attends to multiple needs of the individual, not just his or her drug use'.

\section{Limitations of the study}

Since there was no control group, the personality descriptors cannot be associated with the drug misuse. Moreover, the study at best suggests the possibility of personality disorders occurring in the patients. To determine the occurrence of the disorders, an instrument such as the SCID-II would have to be used. In addition to determining the personality of the patients, there is a need to evaluate their self-concept/esteem using a standardised instrument. 


\section{Conclusions}

Whereas many studies have revealed the association of personality disorders with substance misuse, this study has highlighted the co-occurrence of specific maladaptive personality schemas with substance misuse. To improve the overall prognosis, these schemas can be addressed through specific cognitive-behavioural therapies such as the manualised treatment approach of dual-focus schema therapy (Ball, 1998).

\section{References}

Adamson, T. A., Onifade, P. O. \& Ogunwale, A. (2010) Trends in sociodemographic and drug abuse variables in patients with alcohol and drug use disorders in a Nigerian treatment facility. West African Journal of Medicine, 29, 12-18.

Ball, S. A. (1998) Manualised treatment for substance abusers with personality disorders: dual focus schema therapy. Addictive Behaviors, 23, 883-891.

Butcher, J. N., Graham, J. R., Ben-Porath, Y. S., et al (2001) MMPI-2 Manual for Administration, Scoring and Interpretation. University of Minnesota Press.
Craig, R. J. (1984) A comparison of MMPI profiles of heroin addicts based on multiple methods of classification. Journal of Personality Assessment, 48, 115-120.

Graham, R. J. (1993) MMPI-2: Assessing Personality and Psychopathology (2nd edn). Oxford University Press.

Makanjuola, J. D. A. (1986) The Aro drug addiction research and treatment centre: a first report. British Journal of Addiction, 81, 809-814.

National Institute on Drug Abuse (1999) Principles of Drug Addiction Treatment: A Research-Based Guide (2nd edn). NIH Publication No. 99-4180. Available at http://www.drugabuse.gov/PDF/PODAT/PODAT. pdf (accessed May 2010).

Steffenhagen, R. A. (1980) Self-esteem theory of drug abuse. In Theories on Drug Abuse: Selected Contemporary Perspectives (eds D. J. Lettieri, M. Sayers \& H. W. Pearson), pp. 96-95. National Institute on Drug Abuse. Available at http://archives.drugabuse.gov/pdf/monographs/30. pdf (accessed May 2010).

United Nations International Drug Control Programme (1998) Report of the Rapid Situation Assessment of Drug Abuse in Nigeria. UNDCP.

Verheul, R. (2001) Co-morbidity of personality disorders in individuals with substance use disorders. European Psychiatry, 16, 274-282.

World Health Organization (1992) International Classification of Diseases (10th revision) (ICD-10). WHO.

\section{Public mental health services in Mumbai}

\section{Ajanta Akhuly ${ }^{1}$ and Mrinmoyi Kulkarni ${ }^{2}$}

'Doctoral Research Scholar, Department of Humanities and Social Sciences, Indian Institute of Technology Bombay, Mumbai 400076, India, email ajanta@hss.iitb.ac.in; ${ }^{2}$ Assistant Professor, Department of Humanities and Social Sciences, Indian Institute of Technology Bombay

$\mathrm{M}$ umbai, India's largest city, also has the distinction of being the most populous city in the world. The association between urbanisation and mental illness has been widely documented (Harpham \& Blue, 1995, especially pp. 41-60). Mumbai is characterised by dense slums housing large migrant populations facing stressful lives. The state of publicly funded mental health facilities in Mumbai has special significance in this context, since they are the only resource available to a large economically vulnerable section of the population. The objective of the present study was to evaluate the public mental health services in Mumbai and to identify areas for improvement.

Mental disorders account for $8.5 \%$ of the national burden of disease in India (Peters et al, 2001). Statistics specific to Mumbai are not readily available but, given that $54 \%$ of the city's population of approximately 13 million live in slums, one can assume that this burden would be substantial.

\section{Public healthcare in Mumbai}

The Municipal Corporation of Greater Mumbai (MCGM) and the Maharashtra state government are the two independent bodies responsible for healthcare in Mumbai. The MCGM administers primary care through 185 municipal dispensaries and 176 health posts for out-patient services and public health activities, secondary care through 16 'peripheral' municipal general hospitals and 26 maternity homes in the surburbs, and tertiary care at three teaching hospitals. The state government runs one teaching hospital, three general hospitals and two health units (Dilip \& Duggal, 2004). Only ten of these hospitals have general hospital psychiatric units (GHPUs), which constitute the public mental health facilities for the city.

\section{Method}

The present study assessed nine of these ten GHPUs using the World Health Organization Assessment Instrument for Mental Health Systems (WHO-AIMS) version 2.2 (World Health Organization, 2005). This is a tool for collecting information on the mental health system of a country or region in order to identify weaknesses and make changes. Of the tool's six domains, numbers 2 (mental health services) and 4 (human resources) were adapted (based on a pilot study) for the current study by focusing on questions relevant to GHPUs.

Permission to conduct the study was obtained from the executive health officer of the MCGM. As aggregate data regarding mental health services are not maintained by the municipal public health department, data (hospital records, doctors' records and interviews with doctors) were obtained directly from nine of the GHPUs (one GHPU did not grant permission). Some of the data in the study were taken from doctors' records as opposed to official hospital records and there may be minor inconsistencies between the two, which do not, however, affect the overall trends presented here. 